\title{
Is There a Persuasive Argument for an Inner Awareness Theory of Consciousness?*
}

Abstract: According to (what I will call) an inner awareness theory of consciousness, you are in a (phenomenally) conscious state only if you are aware, in some sense, of your being in the state. This theory is widely held, but what arguments are there for holding it? In this paper, I gather together in a systematic way the main arguments for holding the theory and suggest that none of them is persuasive. I end the paper by asking what our attitude to the theory should be if there is no existing argument for it.

\$1. You are watching a man on a unicycle. Will he fall? Will he balance the flaming torch on his nose? Will the torch burn his moustache? At least for the moment, your attention is completely occupied with him and what he is doing. By contrast, your attention is not occupied with you and what you are doing. At least for the moment, your watching and seeing the man, your own body, and even your own existence, are things to which you are - at least for the moment - completely and happily oblivious.

It is reasonable to assume that in this sort of full absorption case (as we might call it) you are having a conscious experience of some kind. For one thing, not only are you watching the man, there is something it is like for you to watch the man, and that claim is usually taken as sufficient for saying that you are having a conscious experience. Moreover, you are aware of the man and what he is doing - and, again, awareness of this sort is usually assumed to involve consciousness.

But is it also true in this case that you are aware - to put it vaguely at first—of your experience, of being aware of the man?

From an ontological point of view, the economical answer is 'no' or at least 'not necessarily'. Yes you are having a conscious experience, and yes you are aware of the man. But you are not in addition aware of being aware of the man. Indeed, you might think that is the whole point of being fully absorbed. By contrast, according to what I will call an inner awareness theory of consciousness, ${ }^{1}$ the correct answer is 'yes.' According to this theory, if you are having an experience - if you are aware of something at all-you must at some level, in some way, be aware of being aware. So, in this particular case, while it is true you are aware of the man, you are also aware of being aware of the man.

\footnotetext{
*[Acknowledgments]

${ }^{1}$ Terminology: I will exclusively use the phrase 'inner awareness theory' for the theory I have in mind, which I set out in section 3 below. But the theory sometimes goes by other names, e.g. the reflexive theory, the prereflective theory, the self-representational theory, the self-awareness theory. I will not go into the reasons for these different labels here. A recent discussion whose terminology is consonant with mine is McClelland and Farrell 2017.
} 
\$2. Who holds the inner awareness theory? Summarizing a recent historical survey, Greg Janzen (2011; 285; see also Janzen 2008) provides the following names: Aristotle, Brentano, Descartes, Fichte, Freud, Gurwitsch, James, Kant, Leibniz, Locke, and Sartre. And among contemporaries at least the following seem to hold the view in different forms: Armstrong (see Armstrong and Malcolm 1984), Chalmers (2010, 2013), Gennaro (2004), Gertler (2010, 2012), Horgan (2012), Kriegel (2009), Lycan (1996), Montague (2016), Nida-Rümelin (2011) Rosenthal (2005), Strawson (2013), Thompson (2011) and Zahavi (2006).

This is about as impressive a head-count as anyone could ask for. But could it be that everyone here is wrong and the economical answer is right? Well, that's a big question and I won't try to answer it. But what I will do is suggest that, despite its pedigree, there is no persuasive argument for the inner awareness theory, or at any rate no persuasive argument among those offered in contemporary philosophical literature. Hence, so far as these arguments are concerned, we are free to adopt the economical attitude both to full absorption cases and more generally.

My aim is not to identify a single mistake in the arguments for the inner awareness theory; I don't think there is any such single mistake. Instead, I will try to bring out two things. First, when we gather together in a systematic way the main arguments for the theory, what emerges is a series of failures: all of the arguments are unpersuasive, not so much in the sense that they are unsound (though some are unsound, as we will see) but rather in the sense that they have no dialectical force against the person not already convinced of their conclusion. Of course considering the arguments collectively in this way may to some extent involve removing them from their original philosophical context; nevertheless, it is instructive to see the arguments presented one after the other, so the benefits are worth the cost. Second, in many cases what's wrong with these arguments is revealed by some very recent developments in philosophy of mind and related areas - e.g. the semantics of 'what it is like,' the epistemology of introspection, the nature of attention, and the content of perceptual experience. So while it might be that the inner awareness theory has been widely held, recent developments suggest that something different might be just around the corner. ${ }^{2}$

\footnotetext{
2 Three limitations on the present discussion are important to emphasize. First, my concern is exclusively with the persuasiveness of the arguments rather than their soundness-though of course sometimes arguments are unpersuasive because they are unsound. Second, my concern is exclusively with philosophical arguments rather than empirical arguments such as, e.g., those offered in Lau and Rosenthal 2011. Third, my concern is exclusively with the version of the inner awareness theory that I am about to set out, in $\S 3$.
} 
§3. We will turn to the arguments for the theory in a moment; but before doing so, what exactly is it? Well, any version of the inner awareness theory proceeds from the following schematic claim:

(1) $\mathrm{S}$ is in a conscious state $\mathrm{C}$ only if $\mathrm{S}$ is aware (in a certain way) of S's being in $\mathrm{C}$.

Since there are different ways of interpreting (1), there are different versions of the inner awareness theory.

One issue is how to interpret 'conscious state'. Following roughly Block (see, e.g. Block 1997), I will operate with the following three-way distinction:

(2) $\mathrm{S}$ is in a phenomenally conscious (p-conscious) state $\mathrm{C}$ iff there is something it is like for $\mathrm{S}$ to be in $\mathrm{C}$.

(3) $\mathrm{S}$ is in an access conscious (a-conscious) state $\mathrm{C}$ iff $\mathrm{C}$ is poised to play a functional or rational role in S's thought or action.

(4) $\mathrm{S}$ is in a monitoring conscious (m-conscious) state $\mathrm{C}$ iff $\mathrm{S}$ knows or believes (in a certain way) that $\mathrm{S}$ is in $\mathrm{C}$.

In the following, I will focus on (2) and hence on versions of the inner awareness theory that interpret 'conscious state' as 'phenomenally conscious state'.

One might object that this makes our topic much less general that it seemed at first, since it is implausible that all the famous defenders of the inner awareness theory would interpret the theory this way. However, while this may be true, it is also true that most contemporary philosophers who defend an inner awareness theory defend it in something like this form. Hence if our topic is not quite as general is it might be, it is certainly general enough.

Another issue is how to interpret 'aware of.' Once again I will operate with a threeway distinction:

(5) S is (cognitively) aware of a's being $\mathrm{F}$ iff $\mathrm{S}$ knows (or believes) that a is $\mathrm{F}$.

(6) S is (perceptually) aware of a's being $\mathrm{F}$ iff $\mathrm{S}$ perceives (e.g. via the senses) a's being F. 
(7) S is (phenomenally) aware of a's being $F$ iff (a) S is aware of a's being F and (b) it is possible that $\mathrm{S}$ is not (cognitively) aware of a's being $\mathrm{F}$ and is not (perceptually) aware of a's being $\mathrm{F}$.

In what follows I will be concerned for the most part with a version of the inner awareness theory that is neutral as between (5-7); the arguments to follow largely invoke a notion of awareness without specifying which it is, and my criticisms of them likewise will not rely on any particular notion. ${ }^{3}$ Still, it helps the presentation if a single notion is adopted. Hence I will focus on (7) and so on versions of the inner awareness theory that interpret 'awareness' as 'phenomenal awareness.' The extension to other notions of awareness, where relevant, will be left implicit.

A third question about (1) concerns the object of inner awareness. I have talked so far as if that object is a state of affairs, a state of affairs consisting of S's being in a conscious state. But the potential objects of awareness are multifarious: one can be aware of a thing (e.g. an orange), a property (e.g. the colour of the orange), or a fact (e.g. that the orange is (the colour) orange). Once again, for the most part will not matter which of these I operate with, but it helps the presentation if a uniform suggestion is adopted; hence my focus on states of affairs.

Gathering together the suggestions made so far, we arrive at the version of the inner awareness theory that will be our focus:

$\mathrm{S}$ is in a conscious state (phenomenal sense) $\mathrm{C}$ only if $\mathrm{S}$ is aware (phenomenal sense) of a state of affairs, viz., S's being in C.

When I say that there is no persuasive argument for the inner awareness theory, it is (8) I have primarily in mind.

\$4. That I will focus on (8) should not be taken to imply that I think there are no further interpretative questions to be raised about the inner awareness theory. On the contrary, there are least the following issues:

\footnotetext{
${ }^{3}$ The exceptions to this are Arguments 8-9 below which are best understood as invoking the phenomenal notion of awareness in particular, but I will leave this implicit.
} 
(a) The modal strength of (8) — it is reasonable to suppose that (8) is not simply true but necessarily true; this leaves open the precise analysis of the necessity though I will assume in what follows that it is, if true, metaphysically true, i.e. true in all possible worlds without exception.

(b) The epistemic status of (8) - that (8) is necessary leaves open whether it is a priori or a posteriori.

(c) The direction (if any) of explanation-(8) leaves open whether S is in a conscious state because $\mathrm{S}$ is aware or the other way around; it even leaves open whether there is any direction of explanation at all.

(d) Whether the reverse claim is true-(8) says that a necessary condition on being in a phenomenally conscious state is that one is aware of being so, it does not say it is a sufficient condition.

(e) The positive characterization of phenomenal awareness - (8) talks of phenomenal awareness but so far we have only given a negative account of what this is. It is therefore an open question what positive account may be provided if any. ${ }^{4}$

(f) The precise content of awareness-I have talked of being aware of a state of affairs consisting of S's being in C, but in fact it is more plausible that phenomenal awareness admits of an indexical characterization in the sense that it would most likely be captured with the use of an indexical expression such as 'my': on the face of it, I can be aware of $m y$ being in $\mathrm{C}$ and yet not aware of NN's being in C even if I am NN.

(g) The 'one state or two' question - philosophers who hold something like (8) divide between those who say that being in the conscious state and being aware are two distinct states, and those who say that they are one state with two aspects; we will not take up that issue here.

(h) Whether phenomenal consciousness is essential to a state-(8) tells us what must be true if a psychological state is phenomenally conscious, but it leaves open whether phenomenal consciousness is an essential feature of a psychological

\footnotetext{
${ }^{4}$ Since the negative notion of phenomenal awareness I am working with does not tell us positively what it is it does not tell us that it is representational or not. I will assume the former in the text but what I will say also applies to the latter. Hence we accommodate a version of the inner awareness theory suggested by (e.g.) Zahavi (2006) according to which (what I am calling) phenomenal awareness is not a representational notion.
} 
state or an inessential feature; indeed (1) too as I have formulated it leaves this open.

These topics are important and interesting, and if one were to defend an inner awareness theory in detail one would need to have developed views about them. But none of them make a difference to the arguments to follow, and so I will largely leave them aside.

\$5. Now that we have, at least up to a point, a sense of what the inner awareness theory is, we can turn to the arguments for it. Argument 1 is suggested by the list I took from Janzen above. Just below the surface here is a line of thought going roughly like this: many famous and intelligent people have believed the theory, hence (probably) it is true.

Now arguments from authority (which is what this is) are routinely thought to carry very little weight in philosophy. In fact, they are self-undermining, since many famous and intelligent people find arguments from authority implausible. Why then take Argument 1 seriously? Well, a somewhat remarkable fact about the inner awareness theory is how often an argument like this enters the picture. In his discussion of inner consciousness in Psychology from an Empirical Standpoint, for example, Brentano defends a version of the inner awareness theory in part at least on the basis that Mill and Bain held it in England and Aristotle held it in ancient Greece $(2015,137-8)$. And in the present day, similar considerations are quite often mentioned in favour of the theory-indeed that is precisely what Janzen has in mind (see also Strawson 2013).

What then to say about Argument 1? One way to confront it would be to examine the scholarly issues in detail. That is not something I will attempt. ${ }^{5}$ Another way starts from the point that the famous people who in fact advanced the inner awareness theory (assuming they did) either had arguments for it or they did not. If they did not, there is surely no reason to take them seriously no matter how famous they are. If they did, then a reasonable conjecture is that what they had in mind was one or other of the arguments we will consider in the balance of the paper - none of which are arguments from authority. But since, as will see, these arguments are unpersuasive, we should conclude provisionally that the same applies to Argument 1. Let us therefore set it aside and turn to other things.

\footnotetext{
${ }^{5}$ For an extensive discussion of Aristotle's view about consciousness, see Caston 2002.
} 
§6. Argument 2 focuses on the definition of a phenomenally conscious state we adopted above, viz., (2), the 'what it is like' definition. It is often suggested that the inner awareness theory may be extracted directly from this definition, since, to put as Rosenthal does, "as many, myself included, use that phrase, there being something it's like for one to be in a state is simply its seeming subjectively that one is in that state" (Rosenthal 2011, p. 434). If, as seems plausible, Rosenthal's 'seeming subjectively' either is or entails awareness of some sort, ${ }^{6}$ we seem to have a straightforward argument here for the inner awareness theory, which may be formulated as follows:

P1. I am in a conscious state $\mathrm{C}$ iff there is something it is like for me to be in $\mathrm{C}$.

P2. There is something it is like for me to be in C only if I am aware (in some way) of my being in $\mathrm{C}$.

C. Ergo, I am in a conscious state $\mathrm{C}$ only if I am aware (in some way) of my being in $\mathrm{C}$.

$\mathrm{P} 1$ is generated by the definition of a phenomenally conscious state. P2 is motivated by a suggestion like Rosenthal's about how 'what it is like' is to be understood. There is clearly no problem with the validity of the argument, and its first premise is something we have agreed to.

However, the problem with Argument 2 is that Rosenthal's suggestion about 'what it is like' is not persuasive, which is a point I have defended elsewhere (see Author 2016). The correct analysis of 'what it is like', I suggest, may be summarized schematically ${ }^{7}$ as follows.

(9) 'There is something it is like for s to $\mathrm{v}$ ' is true in context $\mathrm{c}$ iff there is in c some way w such that s's v-ing affects s in way w; and

(10) Stereotypically, the quantifier 'there is...some way w' is restricted to ways w is made to feel by $v$-ing.

\footnotetext{
${ }^{6}$ I take it that in using the phrase 'subjective seeming' Rosenthal intends to invoke some notion of awareness without saying exactly what it is. So in this passage he does not have cognitive awareness in mind.

${ }^{7}$ This is a simplified version of what I take the correct analysis to be but the complications will not affect the present point; see Author 2016.
} 
So for example, if you say 'there is something is it like for me to anticipate speaking in public' in a stereotypical context, what you have asserted is that there is some way that (your) anticipating speaking in public makes you feel, i.e. some way you feel in virtue of your anticipating that. Likewise, if you say 'there is something it is like for Bill to have a tingle in his elbow' in a stereotypical context, what you have asserted is that there is some way that Bill feels in virtue of his having a tingle in the elbow.

There are a number of things to say about an analysis of this sort, but, as regards Argument 2, two points are central. First, on this analysis, P2 may easily be denied. For if (9) and (10) are true, it does not follow from the fact that there is something it is like for me to be in $\mathrm{C}$ that I am aware (in some way) of my being in C. All that follows it that there is a way I feel in virtue of my being in C. And that is a different matter. In particular, to say that you feel a certain way in virtue of being in $\mathrm{C}$ is not to say that your being in $\mathrm{C}$ seems to you in any way at all; the crucial relation here is explanatory rather than representational.

Second, on this analysis, there is nothing in the locution 'what it is like' that renders P2 plausible. What makes $\mathrm{P} 2$ seem so plausible, I think, is the thought that emphasizing the prepositional phrase 'for me' in a sentence such as 'there is something it is like for me to be in C' has the effect of bringing out or making salient something that is there in any case, viz., that I am aware of my being in C. But, if (9) and (10) are true, emphasizing this phrase does nothing of the sort. All it does is bring out either (or both) of two things: who is in the state, or who is affected by being in the state, i.e. who feels a particular way in virtue of being in the state. But neither of these things makes P2 plausible.

One might object that (9) and (10) are not true, or more generally that it is controversial what the semantic analysis of 'what it is like'-phrases is. Part of my response is to appeal to my earlier defence of them. But setting that aside, the mere fact that the semantic analysis of 'what it is like' is controversial casts a shadow over Argument 2. For (9) and (10) represent just one proposal in the literature that permits one to deny P2. Proposals distinct from mine but which permit precisely the same thing are defended, for example, in Farrell 2014, Siewert 2012 and Snowdon 2010. Hence, while it may be true that some extant approaches to "what is like' - such as that favoured by Rosenthal—render P2 acceptable, many other approaches do not, and these other approaches are available to opponents of the inner awareness theory. From this point of view, it is hard to see that Argument 2 is persuasive.

One might also object that the inner awareness theory might be resuscitated even if (9) or (10) is true, i.e., if we focus on the phrase 'feel'. For consider: if one feels a certain way, there is a sense in which must be aware of the way that one feels; and in turn if one is aware 
of the way that one feels, it may well be true that one is aware that one feels that way in virtue of some event. ${ }^{8}$ But this suggestion fails to appreciate how 'feels' and related phrases are to be understood. Suppose you feel a certain way in virtue of anticipating speaking in public; you feel your stomach churn for example. Then it is true you must be aware of the churning in your stomach; to feel your stomach churning is to be aware of your stomach churning. But it does not follow that you are aware of your being aware of your stomach churning, and it is the latter notion that is of interest for the inner awareness theory. Similarly, if you feel, and so are aware of, the churning in your stomach, there is a sense in which you are aware of the way that you feel; that is, you are aware of the churning in your stomach. But it does not follow that you are aware that you feel that way in virtue of your anticipating speaking in public; on the contrary, you may only realize much later that this is what made your stomach churn. Hence, while it is plausible that when you have a feeling of any sort, you are aware of something or other, and indeed aware of the way that you feel, this does not make Argument 2 plausible.

Finally, one might object that the phrase 'what it is like' in P2 is used in a technical or stipulated sense. Perhaps Rosenthal in the passage I quoted is simply telling us how he and others intend the phrase to be understood rather than telling us about how to interpret a phrase that is already in use. In that case we might certainly agree that P2 is true, but the problem now is that the argument is invalid. For the phrase 'what it is like' in P1 is not used in a technical or stipulated sense. In P1 the phrase is used in accordance with the definition of a phenomenally conscious state, and this definition involves no stipulation; indeed, it is precisely for this reason that many people have found this definition attractive (see Author 2016). But if the occurrence of 'what it is like' in P2 is technical and in P1 is not technical, Argument 2 is unpersuasive.

\$7. Argument 2 started from something central to the notion of a conscious state, viz. what it is like to be in it. Argument 3 starts from something often held to be central too, viz., 'the transitivity principle' (see, e.g., Rosenthal 2005). According to the transitivity principle, at least stated in full generality, for any kind of conscious state $\mathrm{C}$ - that is, for any of kinds of conscious state described in (2-4) above-you are in C if and only if you are conscious of your being in $\mathrm{C}$. We may state the argument founded on this principle as follows:

\footnotetext{
${ }^{8} \mathrm{I}$ am indebted here to an anonymous reviewer.
} 
P1. I am in a (phenomenally) conscious state $\mathrm{C}$ iff I am conscious of my being in $\mathrm{C}$.

$\mathrm{P} 2$. I am conscious of my being in $\mathrm{C}$ iff I am aware (in some way) of my being in $\mathrm{C}$.

C. Ergo, I am in a conscious state $\mathrm{C}$ only if I am aware (in some way) of my being in C.

$\mathrm{P} 1$ is a statement of the transitivity principle applied to the particular kind of conscious state we have been interested in. P2 is generated by the evident fact for someone to be conscious of something just is for that person to be aware in a certain way of that thing.

However the problem with this argument is that it is far from clear that the transitivity principle is true when applied to phenomenally conscious states; equivalently, it is far from clear that the transitivity principle is true in full generality. Nobody should deny that there is $a$ kind a conscious state for which it (or some counterpart) is true. For example, it is true when applied to monitoring consciousness. But as we have noted monitoring consciousness is not in play.

One might insist that the transitivity principle applies to phenomenal consciousness, or, related to this, insist that phenomenal consciousness is equivalent to a kind of consciousness (such as monitoring consciousness) to which the principle (or some counterpart) applies. But these claims are no more plausible than the inner awareness theory themselves; hence we could not use them to argue persuasively for the inner awareness theory.

One might also object that there must be something right about the transitivity principle as applied to phenomenal consciousness, since so many people seem to hold it. However, as Charles Siewert has pointed out $(2013,244)$, it is possible to honour the idea behind the principle without advancing P1. A different way is to assert something like P1*:

P1* I am in a conscious state $\mathrm{C}$ iff either I am conscious of being in $\mathrm{C}$ or $\mathrm{C}$ consists in a state of being conscious of something.

But since P1* will not generate the inner awareness theory, we may conclude that Argument 3 is unpersuasive. ${ }^{9}$

\footnotetext{
${ }^{9}$ Yet a different way to honor the idea behind the transitivity principle as stated in the text, but without advancing it, would be to advance it in a highly dispositional form, something like this: you are in a conscious state $\mathrm{C}$ if and only if, you would become conscious of being in $\mathrm{C}$ were various background conditions met, e.g., it matters to you whether you are in C, you are rational, and you are capable of being conscious of being in C. I will not explicitly discuss this version of the transitivity principle in this paper, but I think the material
} 
§8. An argument that is closely related to Argument 3 is Argument 4, which is a reductio ad absurdum; that is, it supposes that the inner awareness theory is false, and then tries to generate a contradiction. So suppose (a) I am in conscious state C and (b) I am not aware (in any way) of my being in $\mathrm{C}$ - that is, suppose that (8) is false; then:

P1. If I am not aware (in any way) of my being in $\mathrm{C}$, then $\mathrm{C}$ is not a conscious state.

C1. Ergo, $\mathrm{C}$ is not a conscious state (from P1 and (b))

P2. But $\mathrm{C}$ is a conscious state (from a).

C2. Ergo, $\mathrm{C}$ both is a conscious state and is not a conscious state. Contradiction.

However, the problem here is that P1 is either false or begs the question; in fact, it is just the contrapositive of (8). For example, in the full absorption case above I am aware of the man, and the state I am in is a conscious state-it consists in my being conscious of the man. But it is an open question whether I am aware of my being conscious of the man. Hence the reductio is unpersuasive.

It may be thought that Argument 4 looks better if one incorporates into it the idea of a sub-personal state. ${ }^{10}$ Here the thought is (a) that if I am not aware (in any way) of my being in $\mathrm{C}$, then $\mathrm{C}$ is a sub-personal state, and (b) that if $\mathrm{C}$ is sub-personal, it is not conscious. But the problem here is that from the fact (assuming it to be a fact) that I am not aware of my being in $\mathrm{C}$ it scarcely follows that $\mathrm{C}$ is a sub-personal state. To illustrate, consider the higherorder thought theory such as that suggested by Rosenthal. It is a feature of that theory that many higher-order thoughts - that is, thoughts or beliefs to the effect that one is in a particular state - are such that we are not aware of being in them. But such higher-order thoughts are not sub-personal in any sense. ${ }^{11}$

\footnotetext{
introduced when considering Arguments 7-8 below show that it too provides no reason to endorse an inner awareness theory of the sort we are interested in.

${ }^{10} \mathrm{I}$ am indebted here to an anonymous reviewer

${ }^{11}$ One might point out here that friends of the higher-order theory often use the contrapositive of (8), and relatedly, the contrapositive of the transparency principle mentioned in Argument 3, as an empirical test for consciousness; I am indebted to an anonymous reviewer for this suggestion. That is true, but it provides no support for the inner-awareness theory. For people who reject that theory may well agree that, as an empirical matter, subjects in phenomenally conscious states often believe that they are, and so that, as an empirical matter, subjects who do not believe that they are in such states, are often not in them.
} 
\$9. Arguments 2-4 are linguistic or conceptual in character. Argument 5, by contrast, is epistemological, and concerns the distinctive way in which we come to know about our conscious states. There are two key ideas in this argument. The first is that if you are in a conscious state, the state of affairs that consists in your being in that state is or constitutes an epistemic reason you have to believe you are in it. The second concerns what it is for some state of affairs to be or to constitute an epistemic reason you have to believe something, viz., that it is or constitutes a reason you have to believe something only if you are in some way, in some fashion, aware of that state of affairs. So for example, suppose your neighbour's car being in the driveway is or constitutes a reason you have to believe that your neighbour is home; this could be true, according to the second idea, only if you are in some way aware of your neighbour's car being in the driveway.

Putting these two ideas together we have Argument 5:

P1. If I am in a conscious state $C$, then the state of affairs of my being in $\mathrm{C}$ is or constitutes an epistemic reason for me to believe that I am in C.

P2 If a state of affairs is or constitutes an epistemic reason for me to believe something, then I am aware (in some way) of that state of affairs

C Ergo, if I am in a conscious state C, I am aware (in some way) of the state of affairs of my being in $\mathrm{C}$.

However, there are two problems with this argument. First, it is not at all obvious that a state of affairs is a reason you have to believe something only if you are aware of that state of affairs; that is, it is not obvious that P2 is true. For example, intuitively your seeing your neighbour's car can be a reason for you to believe that your neighbour is home even if you are not aware of seeing your neighbour's car; what is important is that you do see your neighbour's car, not that you are aware of doing so.

Indeed, the epistemological idea lying behind P2, or at least a close variant on that idea, has been called by James Pryor 'the premise principle' and is rejected by him under that name $(2005,189)$. When adapted to our own concerns, the message of Pryor's paper is that there are two legitimate notions of a reason. On the first, a state of affairs is a reason you have to believe something just in case you are aware of that state of affairs and it supports or confirms the belief in question. On the second, a state of affairs is a reason you have to believe something just in case that state of affairs makes it appropriate for you to believe that 
thing, whether or not you are aware of that state of affairs. The problem with P2 is that it assumes that the first notion of a reason is the only legitimate one available; it assumes, as Pryor would say, that the premise principle is true. But since there is another legitimate notion of a reason, $\mathrm{P} 2$ should be rejected.

The second problem with Argument 5 is that it is not clear that P1 is true, at least if it entails that that merely being in a conscious state gives one a reason to believe on is in it. For consider a cognitively unsophisticated creature who is in a phenomenally conscious state; it is having a sensation, say. If P1 is true, while the creature can of course not form the belief that it is in this state, it nevertheless has a reason to do so-indeed, it is rationally appropriate for it to do so. If this is implausible, as I think it is, it is better to say, not that merely being in the state gives you a reason to believe something, but rather that being in a conscious state gives you a reason to believe something, so long as various enabling conditions obtain - that you have certain level of conceptual sophistication, for example, or that you follow various rules of rationality. Of course precisely what these further conditions might be is a matter of debate, but if their presence is required at all, P1 is not true, and Argument 5 should be rejected.

It might be suggested that a better version of Argument 5 may be developed on the basis of premises weaker than P1 and P2. ${ }^{12}$ In the case of P1, for example, it might be said that it does not greatly affect the argument to accept the point just made, and suggest that it is not merely being in a conscious state that gives you a reason to believe you are in it, but rather being in that state along with further enabling conditions. And in the case of $\mathrm{P} 2$, it might be suggested that the best explanation of the fact that $\mathrm{I}$ have a reason to believe that $\mathrm{I}$ am in $\mathrm{C}$ in this situation is precisely that I am aware of being in C. Of course this recasts Argument 5 as an abductive rather than a deductive argument, but that is surely unobjectionable.

However, while it is indeed unobjectionable to recast Argument 5 in this way, it also does not make it more plausible. For if we confront the argument in this form, the crucial question is whether it is the best explanation of the relevant fact that you are aware of being in C. And in the light of the distinction we just took over from Pryor, the answer would seem to be 'no'. For if that distinction is in play, we may say that it is the fact that you are in C, together with the various background enabling conditions, that is or constitutes your reason to believe that you are in C. If so, there is no reason to suppose in addition that you are aware of your being in $\mathrm{C}$, and correlatively, no reason to endorse the inner awareness theory.

\footnotetext{
${ }^{12}$ I am indebted here to an anonymous reviewer.
} 
\$10. Argument 5 is something I have not seen explicitly written up, though I have certainly heard it in discussion many times. Argument 6, however, which is sometimes called 'the memory argument,' is well known in the history of philosophical thought about the inner awareness theory.

As I will consider it here, this argument starts from the following case, which is adapted from Evan Thompson's recent discussion of the memory argument (see Thompson 2011; see also Ganeri 1999). Suppose I (currently) remember that I saw the blue sky yesterday. It follows from this that I did indeed see the blue sky yesterday; you can't (genuinely) remember what is not the case. It also follows that I currently know that I saw the blue sky yesterday; if you (genuinely) remember something, you know it is the case. But it does not follow that yesterday I knew that I was seeing blue sky. After all, it may be that yesterday my mind was so crowded out with other things (my financial position, for example) that I took no notice of the fact, and so did not know, that I was seeing the sky, even though I was.

Now, in this kind of case, there is a puzzle about how I remember seeing the blue sky in the first place. For it is prima facie natural to operate with what we may call the 'knowledge model' of memory. On this model, I remember that I saw the blue sky yesterday just in case (a) I currently know that I saw the blue sky yesterday; (b) yesterday I knew that I saw the blue sky; and (c) my current state of knowledge depends in the right way on my previous state of knowledge. But the problem is that the knowledge model is not applicable in the case we are interested in, since here I precisely did not know yesterday that I saw the blue sky. How then in this case do I remember seeing the blue sky?

As I understand it, the suggestion of Argument 6 is that, if the inner awareness theory is true, we have an answer to this question, since if that theory is true, there is an alternative to the knowledge model that on the one hand preserves its basic structure ${ }^{13}$ and on the other hand applies to the case we have imagined. On this alternative model—which we may call the 'inner awareness model'-I remember that I saw the blue sky yesterday just in case (a) I currently know that I saw it yesterday; (b) yesterday I was (phenomenally) aware of seeing it (something that follows from the inner awareness theory, together with the assumption that I

\footnotetext{
${ }^{13}$ By 'preserves its basic structure' I mean that it preserves the idea that if you remember seeing the blue sky yesterday, you must have been aware yesterday of seeing the blue sky. This feature of the argument is emphasized particularly in Ganeri's 1999 discussion. As we will see in moment, however, the response to the argument I am about to consider precisely denies this.
} 
did consciously see it); and (c) my current state of knowledge depends in the right way on my previous state of inner awareness. How does my current state of knowledge depend on my previous state of awareness? Here I think the suggestion is that my current state of knowledge depends on the fact that I am currently (phenomenally) aware of having seen the blue sky yesterday, and this state of awareness is connected in the right way to the fact that yesterday I was (phenomenally) aware of my seeing the sky.

Now clearly Argument 6 will be successful only if the inner awareness model is the most reasonable alternative to the knowledge model in the case. But the problem is that this is not so. An alternative view starts from the idea that when I saw the sky yesterday I was aware, not of my seeing the sky but of the sky itself, and in particular of the sky's being blue- - here the notion of awareness is the perceptual notion set out in (6) above rather than the phenomenal notion set out in (7). Moreover, if I was (perceptually) aware of the sky's being blue when I saw it, this sort of awareness may persist even when I cease to see it; for example, today I might be perceptually aware of the sky's having been blue yesterday, even if I am not now seeing it. If so, we have another alternative-which we may call the 'perceptual model'-according to which I remember that I saw the blue sky yesterday just in case (a) I know that I saw the sky yesterday; (b) yesterday I saw the sky, and so was perceptually aware of the sky's being blue; and (c) my current state of knowledge depends on my previous perceptual state. How does my current state of knowledge depend on my previous perceptual state? The answer is that my current state of knowledge depends on a current state of perceptual awareness, according to which the sky was blue yesterday, and this state in turn bears the right relation to the state of perceptual awareness I was in yesterday when I saw the sky. Like the inner awareness model, the perceptual model accommodates the sky case; but unlike the inner awareness model, it does not require the truth of the inner awareness theory.

One might object to the perceptual model that one cannot be perceptually aware of the sky's having been blue yesterday. But there are two replies to this. First, the proponent of the inner awareness model requires the analogous thing to be true of phenomenal awareness, since it requires that one is phenomenally aware of having seen the sky yesterday. So it is hard to see why this should be a mark against the perceptual model. Second, we are plausibly committed to the perceptual model anyway. For suppose we focus on a variant on the case we began with in which I remember, not that I saw the sky, but rather that the sky was blue. In such a case, it may similarly be that I did not know yesterday that the sky was blue, and so the knowledge model of memory is inapplicable here too. What alternative is applicable? At this point it is extremely natural to appeal to the perceptual model and suggest that when I 
remember that the sky was blue yesterday, my current state of knowledge is dependent on the current perceptual state I am in — one according to which the sky was blue-and that this current state bears the right sort of relation to the earlier state. So it seems the perceptual model has the resources to explain both the case in which I remember that the sky was blue and the case in which I remember that I saw the sky. Conclusion: Argument 6 is unpersuasive.

\$11. Argument 5 focuses on the epistemology of introspection, and Argument 6 develops that issue by focusing on the interaction of introspection and memory. The next three arguments focus on a different aspect of introspection, viz., that it at least at some level involves a certain sort of attention to one's conscious states. The simplest of these arguments, Argument 7, may be formulated as follows:

P1. If $\mathrm{I}$ am in a conscious state $\mathrm{C}$, it is possible for me to attend to my being in $\mathrm{C}$

P2. If it is possible to attend to my being in $\mathrm{C}$, I am aware of my being in $\mathrm{C}$.

C. Ergo, if I am in a conscious state C, I am aware of my being in C.

The first premise of Argument 7 is driven by the obvious thought that when you are in a conscious state, it must in some sense be possible for you to attend to your being in that state. Of course you may not attend to it-you may be too busy. But it is nevertheless possible to attend to the state. The second premise of the argument is driven by the thought that attention implies awareness, even if the reverse is not true (cf. Block 2000); that is, if you attend to something, you must be aware (in some way) of that thing. The strength of Argument 7 consists in the fact that both of premises have readings in which they are undeniable.

However, Argument 7 commits a modal fallacy, for it conflates two readings of 'it is possible for $\mathrm{S}$ to attend to $\mathrm{x}$ '. On the weak reading, 'it is possible for $\mathrm{S}$ to attend to $\mathrm{x}$ ' does not presuppose that $\mathrm{S}$ is aware of $\mathrm{x}$. For example, suppose I don't know what's in my pocket; it is nevertheless possible for me to attend to what's in my pocket because it is possible for me to come to know what's in my pocket, and attend to what I know. On that reading, however, $\mathrm{P} 2$ is false. All that is true is $\mathrm{P} 2 *$

$\mathrm{P} 2 *$ If it is possible to attend to my being in $\mathrm{C}$, it is possible to be aware of my being in $\mathrm{C}$. 
On the strong reading, 'it is possible for $\mathrm{S}$ to attend to $\mathrm{x}$ ' presupposes that $\mathrm{S}$ is aware of $\mathrm{x}$ : it is simply that $\mathrm{S}$ is not attending to what he or she is aware of. On that reading however, $\mathrm{P} 1$ begs the question, because it assumes from the start one is aware of the conscious state. ${ }^{14}$

One might object that, even if the weak reading is in play, the conclusion of the argument is still interesting because it shows that it is possible to be aware. But at this point we need to remind ourselves that 'aware' can mean different things, and the argument does not make it clear which notion is in play. If 'aware' here is read as cognitive awareness, it is not clear how interesting it is to be told merely that if one is in the state it is possible to know that one is-very few philosophers, if any, will want to say that no version of this claim is true. ${ }^{15}$ But if 'aware' is read as phenomenal awareness, it is not clear that even P2* is true. After all, why should the mere fact that is possible for me to attend (in some way or other) to my being $\mathrm{C}$ - for example by coming to know that I am in $\mathrm{C}$, and attending to what I knowsuggest that it is possible to be phenomenally aware of that state? If there is no answer to this question, Argument 7 is unpersuasive.

\$12. The next argument from attention may be seen as bolstering Argument 7 on precisely this point, but it also deserves separate treatment, in part because it introduces a new idea, and indeed four new ideas in the discussion. ${ }^{16}$ The first is the idea of concept possession and deployment: in order to be cognitively aware of your being in a conscious state you would need to possess and deploy a concept of that state. The second is that simply being in the state is not sufficient for you to possess or deploy a concept of the state; cognitively unsophisticated creatures, for example, might be in the state and not possess or deploy any concept of it. The third is that to possess or deploy the concept one must attend in some way

\footnotetext{
14 The modal fallacy noted in the text is relevant also to another argument for the inner awareness theory suggested in various places by Rosenthal, viz., the argument from reportability (see e.g. Rosenthal 2005, esp. pp. 289-94). According to this argument, roughly, from the fact that it is possible for me to report being in the state it follows that I must be aware of it. I have not discussed this argument in the text since, as Rosenthal notes, its focus is on particular form of the inner awareness theory, viz., the one in which the background notion of awareness is cognitive awareness, whereas as I noted my focus is mainly on versions that are neutral on this matter. But in any case, I believe it fails in the same way that Argument 7 does. For, from the fact that it is possible for me to report being in a state it does not follow that I am aware of being in it; all that follows is that it is possible for me to be or become aware of being in it.

${ }^{15}$ Nor does conceding this grant anything to the inner awareness theory, since as I noted in section 4 according to it (8) is necessary and hence there is a necessary connection between being in the state and being aware of it.

${ }^{16}$ I take an argument like this to be suggested by David Chalmers who writes "the clearest cases of direct phenomenal concepts arise when a subject attends to the quality of an experience and forms a concept wholly based on attention to that quality" $(2010,267)$.
} 
to the state. And the fourth is that the attention at issue here cannot be of a cognitive variety, since it is in operation prior to any concept being possessed or deployed-we may call this a phenomenal notion of attention, and understand it roughly on the model of phenomenal awareness as stated in (7) above.

The argument founded on these ideas, Argument 8, can be expressed as follows:

P1. If $\mathrm{I}$ am in a conscious state $\mathrm{C}$ it is possible for me to form (or deploy) a concept of C.

$\mathrm{P} 2$. If it is possible for me form (or deploy) a concept of $\mathrm{C}$ then it is possible for me to (phenomenally) attend to my being in $\mathrm{C}$.

P3. If it is possible for me to (phenomenally) attend to my being in $\mathrm{C}$, then I am (phenomenally) aware of my being in C.

C. Ergo, if I am in a conscious state C, I am aware (in some way) of my being in C.

One objection one might make to this argument is that P3 is problematic for the same reason that $\mathrm{P} 2$ of Argument 7 is problematic: they both infer from what is possible to what is actual. But setting that aside, there is a much more fundamental problem with Argument 8, and this is that P2 is implausible: on the face of it, it is perfectly possible for me to form or deploy a concept of $\mathrm{C}$, even if I do not attend to my being in $\mathrm{C}$.

To illustrate, it is convenient to divide the issue into two cases: the deployment case (which concerns deploying a concept you already possess) and the formation case (which concerns coming to possess a concept you did not previously possess). As regards deployment, it is quite a common view in the philosophy of introspection that if one is in a conscious state, and if one attends to the question of whether one is in the state, and if one is rational and has sufficient cognitive sophistication, one will believe that one is in state (see e.g. Shoemaker 1996, 2009). This sort of view requires you attend to something in order to believe that you are in $\mathrm{C}$ (and so in order to deploy a concept of $\mathrm{C}$ ), but it is does not require that you attend to your being in $\mathrm{C}$. What it requires you to attend to is the question of whether you are in C. Since attending to a question is one thing, and attending to state you are in is something else, $\mathrm{P} 2$ is false in the deployment case — or at any rate is false if this widely held view in philosophy of introspection is true.

As regards the formation case, it is true that merely being in a conscious state is not sufficient for you to form a concept of $\mathrm{C}$, but it certainly doesn't follow that attending to your being in $\mathrm{C}$ is necessary. The notion of attention that we have been operating with throughout 
is a personal-level notion; it is a person who attends or is aware of something. But to explain how you come to be possess a concept you do not already have, it is quite unclear that any personal-level explanation is required, especially when the concepts are of conscious states themselves. One might think rather that what is required is that one is built cognitively in the right sort of way at the sub-personal level. On the other hand, if no personal-level explanation is necessary, $\mathrm{P} 2$ is false in the formation case.

\$13. Arguments 7-8 focus on the possibility of attention, but David Chalmers has recently suggested a third style of attention argument for the inner awareness theory, which is focused on actual cases. ${ }^{17}$ "One case", he writes:

...involves attention to phenomenal blurring, the shift from clear to blurry vision that takes place when one squints, for example. During this process one clearly is aware of and attends to a change. While one attends to an external object here, one does not represent it as changing. One plausibly attributes fine-grained properties to it at the first stage and coarse-grained properties at the second stage, but these properties are entirely consistent with one another, so no change is represented. Rather, the change is entirely in one's phenomenal properties: from fine-grained experience (involving awareness of fine-grained properties) to coarse-grained experience (involving awareness of coarse-grained properties). I think that one's awareness of blurring is clearly awareness of this phenomenal change, and likewise, one's attention to blurring is clearly attention to a phenomenal change. (Chalmers, 2013, p. 347) ${ }^{18}$

A different case involves the change of experiences one has when one turns one's head:

In a normal perceptual mode, look around a still room. Nothing seems to change. Now switch to an introspective mode, and look around again. One is now quite clearly aware of a change: for example, when objects disappear from sight. But nothing in the world seems to change. (If one objects that one's head or eyes seem to

\footnotetext{
${ }^{17}$ As Chalmers notes, Geoffrey Lee has argued similarly in unpublished work.

${ }^{18}$ Chalmers notes that A.D.Smith (see Smith 2008) uses the case of blur to argue against various forms of transparency or diaphanousness in philosophy of mind. But as I understand him the form of the thesis of transparency that Smith argues against is a very strong one; it is that one cannot attend at all in any way to one's phenomenal experience. One does not need to hold the inner awareness theory to agree with Smith that that thesis is implausible.
} 
move, switch the case to a covert change in attention.) The change one is aware of is a change in one's experience: a phenomenal change. I think that likewise, when in the relevant introspective mode, even before looking around the room, one is aware of phenomenal features of one's experience. (2013, p. 347)

As I understand it, the argument that Chalmers is setting out on the basis of these examples, Argument 9, is as follows. Its premise is that in these examples - the blur example and the head-turning example - there is a process of phenomenal change we can undergo that has the following features: (a) the states that constitute different phases of the process are different from each other - that is what makes it a process of change; (b) these states do not, either individually or collectively, represent a change in the world; and (c) we can be aware of and attend to the change we undergo. Its conclusion is that the inner awareness theory is true.

But the response to this argument is that the premise does not support the conclusion. There is indeed a phenomenal change of the sort Chalmers describes, and it is indeed the case that the states do not represent a change in the world. Moreover, it is true in general we can be both aware of and attend to these changes; for example we can come to know that they obtain, and then attend to what we know. But none of these facts by themselves suggest that when we undergo a change of this sort, we are phenomenally aware of it.

One might respond that one must phenomenally attend to the change in order that we could become cognitively aware of it. (It may be that this is what Chalmers has in mind when he speaks of 'the relevant introspective mode.') But this suggestion returns us to the points made against Argument 8. As we saw, it is not at all clear that to deploy a concept of a phenomenal state we are in, or to form a new concept of such a state, we need to attend to the state. The same thing applies when we consider changes among the states we are in rather the states themselves; that is, it is not all clear that to deploy a concept of a phenomenal change we are undergoing, or to form a new concept of such a change, we need to attend to the change.

One might also respond that what we have said does not take into account a crucial point that generates Chalmers's interest in these examples in the first place, viz., that the conscious states at issue here do not individually or collectively represent a change in the world. Perhaps what he has in mind is that, while these conscious states do not represent a change in the world, they do involve a representation of a change of some sort, prior to our coming to know about them; and this suggests that what they represent is a change in themselves. But to this my response is simple. It is quite unclear that there is a representation 
of change of that sort here at all. At least prior to our coming to know that we are in the states, there is change of representation but there is no representation of change. If so Argument 9 is unpersuasive.

\$14. The final argument I want to consider for the inner awareness theory, Argument 10, starts from an important point about conscious states, viz., that it is often the case, as Susanna Siegel puts it, that such states "present the world from the subject's perspective both in space and in time. If one tried to characterize the perspective aspect of contents in language, it would be natural to use indexical expressions for spatial properties, for the subject herself, and for times" (Siegel, 2010). In the full absorption case above, for example, it is natural to say that the man on the unicycle is not simply seen, but seen from here, as over there, as slightly to the left, as coming toward you, and so on. We might express this point by saying that conscious states admit of an indexical characterization, that is, that if we try to capture these states in language we would need to use indexical expressions such as 'here', 'there', 'now', 'me' etc.

Now there are many interesting questions that emerge as a consequence of this observation, but here I will concentrate simply on the suggestion that there is some support here for the inner awareness theory. For it is often suggested - and this is Argument 10 that from the premise that conscious states admit of an indexical characterization, one can conclude that the inner awareness theory is true (cf. Kriegel 2009, Zahavi 2005). ${ }^{19}$

But the problem with this argument is again that the premise does not support the conclusion..$^{20}$ To illustrate, consider a picture of a book on a table in an otherwise an empty room. The picture admits of an indexical characterization too. It is natural to say that the book is not simply presented, but is presented from here, as over there, as slightly to the left, as lying at some distance, and so on. Intuitively this conveys part of the content of the picture, part of the story told by the picture about the book and the room. If we tried to say what the picture depicts but did not say these things or anything equivalent, we would have

\footnotetext{
${ }^{19}$ In the text I assume that it is conscious states that admit of an indexical characterization. Could one assume instead that phenomenal awareness admits of such a characterization? After all, as I indicated in section 4, it is very plausible that it does. However, the problem with this interpretation of the argument is that it brings us no closer to the truth of the inner awareness theory, since that reflexive awareness has a certain sort of content does not entail that if you in a conscious state you are in state of reflexive awareness with that content.

${ }^{20}$ The use of depictive representation in the text is inspired by Bernard Williams' use of it in a related context (see Williams 1973). For a somewhat similar use also in the context of reflexive theories, see Grünbaum \& Zahavi 2013, esp. pp. 230-233.
} 
left something out. But none of this entails that the picture itself is aware of what it depicts, whatever that might mean. Nor does it entail that it is part of the content of the picture that the picture itself exists or that some viewer exists; on the contrary, the picture is of a room that is empty apart from the book. The same thing is true, mutatis mutandis, in the case of conscious states. It is true that conscious states admit of indexical characterizations. But since little follows about the states themselves, Argument 10 is unpersuasive.

It may be objected that while this counterexample is persuasive when our focus is on perceptual cases, which are perhaps analogous to pictures, it is less persuasive if we widen our view to conscious states in general. ${ }^{21}$ But I think a point of principle emerges here if we stand back and ask more generally what we can conclude from the claim that conscious states admit of indexical characterizations. In fact this issue is highly controversial in the literature, but one common proposal is the so-called centered worlds approach (cf., e.g., Brogaard 2012). On this view - to put it very roughly - the content of conscious states that admit of indexical characterizations is or determines a set of centered worlds, where a 'centered world' is a pair of a possible world and a center, i.e. a designated individual and a time. Hence we can say that the content of the state in the full absorption case is a set of centered worlds at which the man on the unicycle is to the left of the individual designated as the centre.

Now as I say the centered worlds approach is a very big topic; we are not going to go into it here. For us the crucial points are as follows. First, the centered world approach applies not just to perceptual states but to conscious (and indeed non-conscious) states in general. Second, there is no support here for the inner awareness theory. For one thing, it does not follow from the idea that the content of a conscious state is or determines a set of centered worlds that the individual designated at the centre $i s$ the individual who is in the state in question. Moreover, even if we focus on cases in which this is true, it does not follow that the individual who is in the state is aware of being in the state. All that follows is that the content of the state involves an individual who is in fact the person who is in the state. Putting these two together, Argument 10 is unpersuasive in general, and not simply in the perceptual case.

It might also be objected that there is a much more straightforward version of Argument 10 that I have neglected to consider. This more straightforward argument asserts directly (a) that the content of the state in the full absorption case is (something like) there is a

\footnotetext{
${ }^{21} \mathrm{I}$ am indebted here to an anonymous reviewer.
} 
man on a unicycle now and (b) that 'now' means 'at the same time as this very thought'. ${ }^{22}$ However, while these two claims may lead to the inner awareness theory, both are highly problematic. We cannot uncritically say that the content of the state is 'there is a man on a unicycle now'. All we can say that we may use indexical language to capture the content in question; that is why I said above that these states admit of an 'indexical characterization'. Moreover, if we go on to ask what this fact tells us about the content of the state, the answer may well be something like the centred worlds account, and as we have seen this brings us no closer to the inner awareness theory. Nor is it plausible to think that 'it is raining now' means 'it is raining at the time of this very thought'. If it did, then 'it is raining now but I don't think it is' would be a literal contradiction when - notoriously-it is not a literal contradiction. In sum, there is no more straightforward way to formulate Argument 10 than the one I have already considered.

\$15. If you keep putting questions to nature, and nature keeps saying no, it is reasonable to think that you are on the wrong track. In the case of the inner awareness theory of consciousness, we have put repeated questions to nature; we have tried repeatedly to formulate arguments for its truth. But nature keeps saying no; the arguments are unpersuasive. A natural inference is that we are on the wrong track, and the inner awareness theory is false.

Should we draw that inference? Well it is possible that the list of arguments I have considered is not exhaustive. For example, maybe there are arguments yet to be developed, or existing arguments I have missed, or better versions of the arguments I have considered. If so, the present paper may be read as a challenge to produce those arguments. ${ }^{23}$ Another possibility is that while there is no good argument for the theory, there is also no good argument against it. If that were the case, the inner awareness theory would be neither ruled in nor ruled out, at least from a philosophical point of view. But in fact I don't think there is no good argument against it. For consider the full absorption case again. ${ }^{24}$ As I noted, the economical thing from an ontological point of view to say in such cases is that I am aware of the man but not aware of my being aware. This by itself is a consideration against the inner awareness theory, though admittedly of a defeasible sort. In other words, if the list of

\footnotetext{
${ }^{22} \mathrm{I}$ am indebted here to an anonymous reviewer.

${ }^{23}$ It is worth remembering at this point also that I am concerned only with philosophical arguments for the inner awareness theory in this paper.

${ }^{24}$ Another argument against the inner awareness theory is the well-known regress argument. I have discussed this argument in detail elsewhere and so will set it aside here-see Author 2017; see also Siewert 2013.
} 
arguments I have considered is exhaustive, and if my analysis of them is correct, it is most reasonable to conclude on grounds of economy that the inner awareness theory is false. That is not to deny that connections between consciousness and awareness of the sort described by the inner awareness theory obtain in some possible type of mind, only that they need not, and moreover do not, obtain in ours.

\section{References:}

Author 2016

Author 2017

Armstrong, David and Malcolm, Norman 1984: Consciousness and Causality: A Debate on the Nature of Mind. Oxford: Blackwell.

Block, Ned. 1997. "On a Confusion About a Function of Consciousness.” In The Nature of Consciousness, edited by N. Block, O. Flanagan, and G. Guzeldere. Cambridge, MA: MIT Press.

Block, Ned. 2000. “Mental Paint". In Hahn, M and Ramberg, B (eds) 2000 Essays in Honor of Tyler Burge Cambridge, MA MIT Press.

Brogaard, Berit 2012 “Centered Worlds and the Content of Perception”, in Steven Hales (ed.) Blackwell Companion to Relativism, Oxford: Blackwell (2011): 137-158.

Brentano, F. 2015 Psychology from an Empirical Standpoint English London: Routledge Classics (Original Publication 1974.)

Caston, Victor 2002 'Aristotle on Consciousness'. Mind, Volume 111, Issue 444, October 2002, Pages 751-815.

Chalmers, D. 2010 The Character of Consciousness New York: Oxford University Press.

Chalmers, D. 2013 'The Contents of Consciousness: Reply to Hellie, Peacocke and Siegel, Analysis 73 (2): 345-368 (2013)

Ganeri, J. 1999 “Self-intimation, Memory and Personal Identity”, Journal of Indian Philosophy 27: 469-483, 1999

Gennaro, Rocco (ed.) 2004: Higher Order Theories of Consciousness. Amsterdam: John Benjamins.

Gertler, B. 2010 Self-Knowledge London: Routledge

Gertler, B. 2012 "Renewed Acquaintance" in Smithies, D and Stoljar, D. (eds) 2012 Consciousness and Introspection New York: Oxford University Press pp 93-128

Grünbaum T \& Zahavi, D, 2013 "Varieties of Self-Awareness" in Fulford, K.W.M et al (eds)The Oxford Handbook of Philosophy \& Psychiatry Oxford (2013), 221-239. 
Farrell, J. 2014 'What it is like' talk: What it is like. PhD Dissertation, Australian National University.

Horgan, T. 2012 'Introspection about Phenomenal Consciousness: Running the Gamut from Infallibility to Impotence.' In D. Smithies and D. Stoljar (eds.), Introspection and Consciousness. Oxford (2012), 405-422

Janzen, Greg 2008: The Reflexive Nature of Consciousness. Philadelphia/Amsterdam: John Benjamins.

Janzen Greg 2011: 'In Defense of the What-It-Is-Likeness of Experience' The Southern Journal of Philosophy 49, pp. 271-93

Lau, H and Rosenthal D 2011. 'Empirical support for higher-order theories of conscious awareness' Trends in Cognitive Sciences August 2011, Vol. 15, No. 8, pp. 365-373.

Lycan, William G. 1996: Consciousness and Experience MIT Press, Cambridge MA Kriegel, Uriah 2009: Subjective Consciousness: A Self-representational theory. New York: Oxford University Press

Farrell, Jonathan and McClelland, Tom (2017) "Editorial: consciousness and inner awareness." Review of Philosophy and Psychology, 8 (1). pp. 1-22. doi:10.1007/s13164$\underline{017-0331-\mathrm{X}}$

Montague, M. 2016 The Given: Experience and its Content. Oxford: Oxford University Press

Nida-Rümelin, M 2011 'Phenomenal Presence and Perceptual Awareness: A Subjectivist Account of Perceptual Openness to the World' Philosophical Issues, 21 (1), 2011, pp. $352-83$

Pryor, J. 2005 “There is Immediate Justification” in Matthias Steup and Ernest Sosa (eds) Contemporary Debates In Epistemology Oxford: Blackwell Publishing, pp. 181-201.

Rosenthal, D. 2005. Consciousness and Mind Oxford: Clarendon Press, 2005.

Rosenthal, David 2011: 'Exaggerated Reports: Reply to Block’ Analysis Vol 71 Number 3 July 2011 pp. 431-37

Shoemaker, S. 2009 “Self Intimation and Second Order Belief” Erkenntnis 71: 35-51

Shoemaker, Sydney. 1996. The First Person Perspective and Other Essays. Cambridge: Cambridge University Press.

Siewert, C. 2012 'The Phenomenology of Introspection' in D. Smithies and D. Stoljar, (eds) 2012:. Introspection and Consciousness, Oxford University Press, 259-93. 
Siewert, C 2013 'Phenomenality and Self-Consciousness' in U.Kriegel (ed) 2013

Phenomenal Intentionality New York: Oxford University Press, pp 235-259

Siegel, Susanna, 2015 "The Contents of Perception", The Stanford Encyclopedia of Philosophy (Spring 2015 Edition), Edward N. Zalta (ed.), URL = $<$ http://plato.stanford.edu/archives/spr2015/entries/perception-contents/>.

Smith, A.D. 2008. Translucent Experiences. Philosophical Studies 115:225-244.

Snowdon, Paul 2010: 'The What-it-is-Like-ness of Experience' Southern Journal of Philosophy, 48 (1): pp. 8-27

Strawson, G. 2013 'Self-intimation' in Phenomenology and the Cognitive Sciences 12 pp 44-73.

Thompson, E. 2011 "Memory and Reflexive Awareness". In Mark Siderits, Evan Thompson, and Dan Zahavi (eds) Self, no Self? Perspectives from Analytical, Phenomenological, and Indian Traditions Oxford: Oxford University Press Williams, B. 1973. Problems of the Self. Cambridge: Cambridge University Press Zahavi, D. (2006) “Thinking about Self-Consciousness: Phenomenological Perspectives.” In U.Kriegel and K. Williford (eds.) Self-Representational Approaches to Consciousness. Cambridge MA: MIT Press 